\title{
ATHLETIC IDENTITY AND CONFORMITY TO MASCULINITY BASED ON DIFFERENT TYPES OF SPORTS
}

\section{by}

Julie James

\author{
A thesis \\ submitted in partial fulfillment \\ of the requirements for the degree of \\ Master of Science in Kinesiology \\ Boise State University
}

May 2019 
(C) 2019

Julie James

ALL RIGHTS RESERVED 


\title{
BOISE STATE UNIVERSITY GRADUATE COLLEGE
}

\section{DEFENSE COMMITTEE AND FINAL READING APPROVALS}

\author{
of the thesis submitted by
}

Julie James

Thesis Title: Athletic Identity and Conformity to Masculinity Based on Different Types of Sports

Date of Final Oral Examination: $\quad 26$ October 2018

The following individuals read and discussed the thesis submitted by student Julie James, and they evaluated her presentation and response to questions during the final oral examination. They found that the student passed the final oral examination.

Shelley Lucas, Ph.D. Chair, Supervisory Committee

Eric M. Martin, Ph.D. Member, Supervisory Committee

Laura Jones Petranek, Ph.D. Member, Supervisory Committee

The final reading approval of the thesis was granted by Shelley Lucas, Ph.D., Chair of the Supervisory Committee. The thesis was approved by the Graduate College. 


\section{ACKNOWLEDGEMENTS}

I want to give a huge thank you to Dr. Shelley Lucas, who spent countless hours over my years at Boise State University helping me create, execute, and finalize this thesis. Her brainstorming and incredible advice throughout this process has allowed me to overcome many logistical circumstances that we encountered. The patience and support she provided were unmatched and extremely appreciated. I would also like to thank Dr. Martin for his statistical expertise and encouragement and Dr. Laura Jones Petranek for her honest and valuable counsel. Additionally, I am so grateful for the continuous support from my family and my husband during my time in the graduate program. Their understanding and love supported me through the process of this thesis. 


\begin{abstract}
Introduction: Researchers have examined hegemonic masculine norms and athletic identity in regard to athletes in order to understand how traits such as aggression, violence, heterosexual self-presentation, exclusivity, etc., are positively reinforced in America's sporting culture. The expectations for aggressive sport athletes to use their bodies as weapons, play through injuries, and suppress their empathy makes transitioning into their off-field daily lives difficult. Although researchers have examined how and why college football players conform to masculine norms and an athletic identity, little is known about how these constructs do or do not manifest within the athletes of different types of sports. Purpose: The purpose of the current study was to examine college males' retrospective sporting experiences from high school in order to better understand collision, contact, and non-contact sport athletes' attitudes regarding masculine norms and athletic identity. Participants: The participants $(n=94)$ were male students enrolled in Kinesiology courses at a Pacific northwestern university. Methods: Each participant completed a 15-minute survey consisting of demographic questions concerning their athletic background, a shortened version of the Conformity to Masculine Norms Inventory (CMNI-46), and the Athletic Identity Measurement Scale (AIMS). Data Analysis: Descriptive statistics were collected regarding the participants' age, year in school, ethnicity, guardians' education level, and high school sport experience. Two MANOVAs were conducted to examine the connections, if any, between the type of sport college males excelled at most during their high school years and the CMNI-46 and
\end{abstract}


the AIMS. If the MANOVA was significant, a follow-up univariate ANOVA was conducted. Lastly, a bivariate correlation was conducted for all the subscales of the two instruments. Results: The MANOVA investigating sport type differences for the CMNI46 was statistically significant with follow-up univariate ANOVAs indicating that collision athletes were more violent than contact athletes. Discussion: This finding offers some understanding of the culture surrounding collision sports and its influence on the athletes participating. 


\section{TABLE OF CONTENTS}

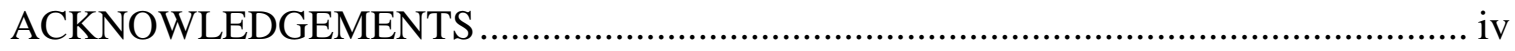

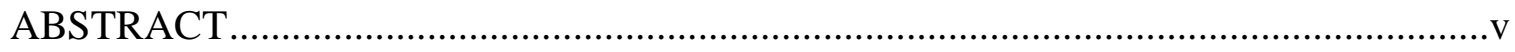

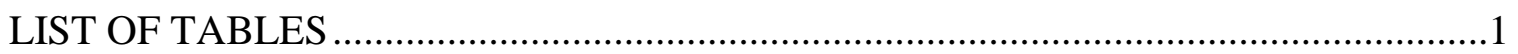

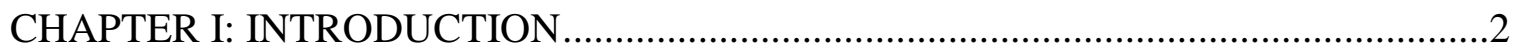

The Socialization of Athletes in Contact Sports ................................................

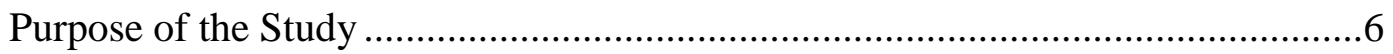

Research Question(s) .....................................................................6

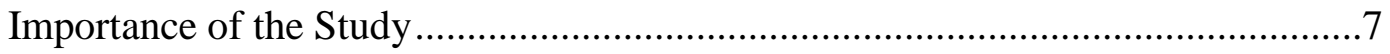

CHAPTER II: LITERATURE REVIEW ............................................................

Social Learning \& Social Identity Theories..................................................

Violent Sports Attract Violent Athletes ........................................................... 13

Understanding the Culture of American Contact Sports ..................................15

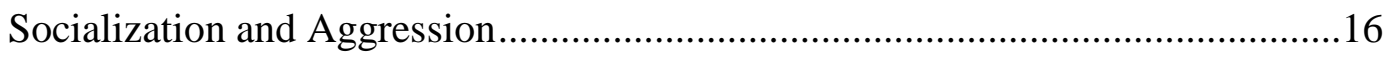

Normalization of Violence \& Acceptance of Domestic Violence .......................17

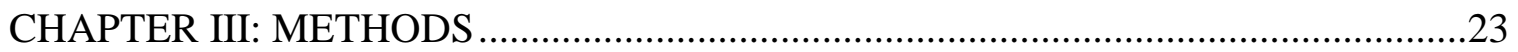

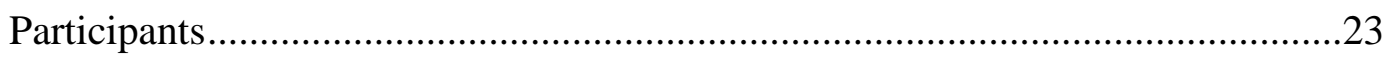

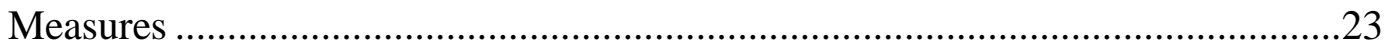

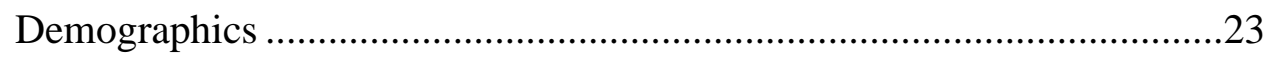

Conformity to Masculine Norms ........................................................24

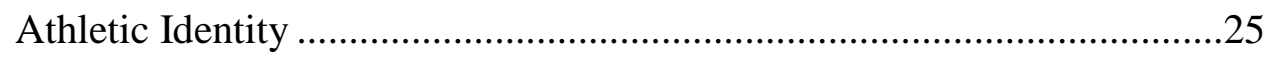


Procedures

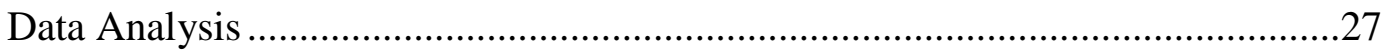

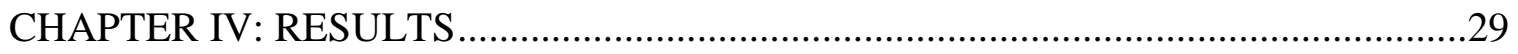

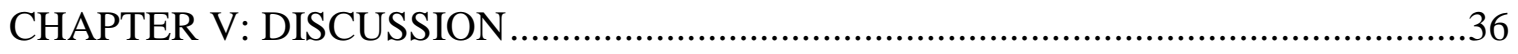

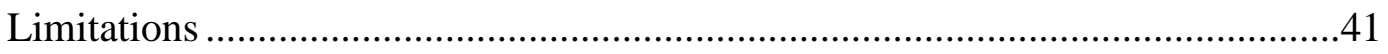

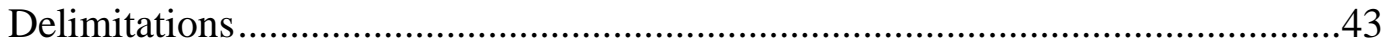

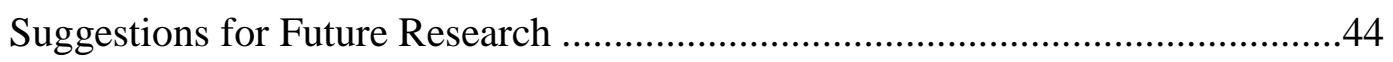

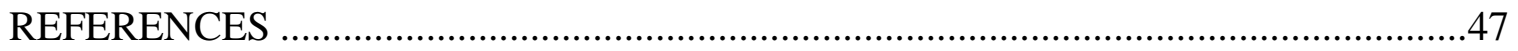

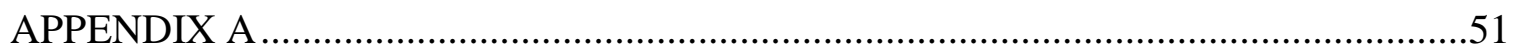

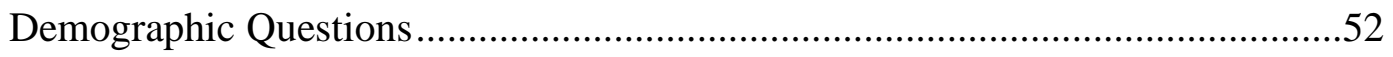

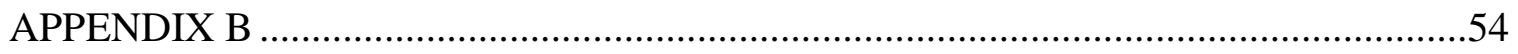

Conformity to Masculine Norms 46 and Athletic Identity ....................................55

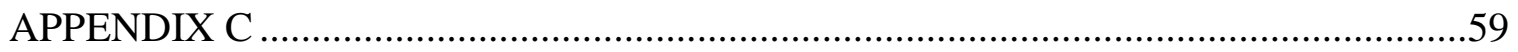

7-Item Version of Athletic Identity Measurement Scale (AIMS) …………..........60

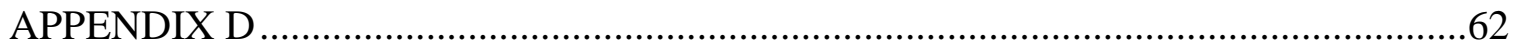

Consent Page for the Survey ...........................................................................63 


\section{LIST OF TABLES}

Table $1.1 \quad$ Operational Definitions.................................................................. 8

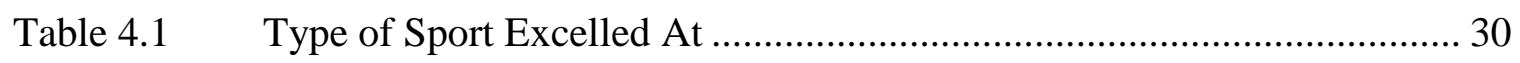

Table 4.2 Sports Played During High School Years............................................ 30

Table 4.3a Means and Standard Deviations for CMNI Subscales........................... 32

Table 4.3b Means and Standard Deviations for AIMS Subscales ........................... 32

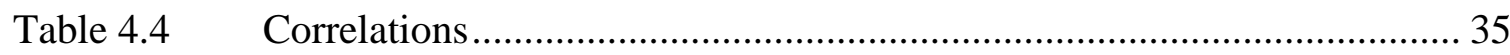




\section{CHAPTER I: INTRODUCTION}

Researchers have examined the construct of masculinity as a central aspect of athletes' behavior within the culture of American sports (McDonald, 1999; Parent \& Moradi, 2009; Steinfeldt \& Steinfeldt, 2012). Steinfeldt and Steinfeldt (2012) note, "Hegemonic masculinity is the theoretical framework for masculinity that has been extensively used to conceptualize masculinity in sport, particularly in football” (p. 117). While a universally accepted definition of hegemonic masculinity has not been agreed upon, most social scientists agree that it includes concepts such as aggression, courage, dominance, respect, honor, risk-taking (Fields, Collins, \& Comstock, 2007), toughness, self-reliance, and stoicism (Clay, 2012). Using this framework, researchers found that heterosexuality, competitiveness, and aggressiveness are socially dominant and culturally ideal traits that American males seek to obtain at a young age (Clay, 2012; Messner, 2015; Steinfeldt \& Steinfeldt, 2012). Male athletes tend to display these hegemonic masculine attributes more so than the general population (Steinfeldt \& Steinfeldt, 2012), which parallels the large numbers of male athlete perpetrators of violence against women on college campuses.

Differences in athlete behavior based on the type of sport one plays have also been investigated in sport psychology (Keeler, 2007). For the purposes of this study, collision, contact, and non-contact sports are examined as three categories of sport. Collision sports feature player-to-player collisions as a regular and expected part of the game, whereas contact sports allow for physical contact, but overt collisions are against the rules. Non-contact sports are those in which contact between opponents is considered illegal (Keeler, 2007). The amount of contact in sports has an influence on the culture 
surrounding those sports. Conformity to masculinity (Steinfeldt \& Steinfeldt, 2012), an abundance of aggression (Keeler, 2007), and the possibility of violence (McCray, 2015) are aspects that have been investigated as playing a large role in the culture of American collision and contact sports.

\section{The Socialization of Athletes in Contact Sports}

Coaches and players know that being aggressive is an important part of most contact sports (Messner, 2015; Young, 1993). However, some coaches push players to take it too far, as illustrated by this quote from former NFL football coach Steve Mariuchi, "Coaches want tough guys, players who love to hit and fly around and do things that are mean and nasty...if you can have one or two players who are a little overaggressive, that's great" (Messner, 2015, p. 446). Coaches' expectations of male aggressive-sport-athletes to use their bodies as weapons on the field have made it difficult to transition back into their daily lives outside of sport (Messner, 2015; Pappas, McKenry, \& Catlett, 2004). Athletes learn to suppress their empathy, which is reinforced when coaches, fans, and teammates applaud their aggressive behaviors (Messner, 2015). When hegemonic masculinity and aggression are expected and celebrated, violence becomes normalized within contact sports (Young, 1993).

The normative idea of using their bodies as weapons begins early on in boys' lives (Messner, 2015; Young, 1993). They are taught that being vulnerable or weak is not how a man in American society is supposed to act (Young, 1993). Sports are an avenue for young boys to explore their masculinity and aggression in a legal and socially acceptable manner (Messner, 2015). Coaches and professional athletic role models teach young athletes these traits by modeling them and then using praise to fortify that type of 
behavior (Fields et al, 2007; Murnen \& Kohlman, 2007). By the time male athletes reach the more competitive levels of sports, they have learned to be forceful and assertive with their bodies, and to dehumanize and objectify their opponents (Messner, 2015; Young, 1993).

The reinforcement of these masculine ideals within male athletes occurs for many reasons. A bond created within male teams promotes an intensified masculine, homophobic atmosphere that pressures teammates to conform in order to fit in with their peers (Marasescu, 2014; Steinfeldt \& Steinfeldt, 2012). In other words, the team creates group norms and if a teammate does not conform to those standards, social consequences result (e.g., being ridiculed or excluded) (Messner, 2015). Marasescu (2014) also found that coaches and players use aggressive behavior more if they believe it would improve their chances of winning or being successful. The need to win might not only be motivated by the combative nature of collision and contact sports, but also by wanting to improve their status on the team or at school (McCray, 2015). Not conforming to these masculine behaviors is harshly looked down upon, especially within the hyper-masculine culture of certain American sports (e.g., football and hockey) (Young, 1993). For example, coaches often use degrading phrases (termed the "doomsday weapon") such as, "you sissy" to threaten athletes' masculinity so players continue to be aggressive and to persist through the pain of an injury (Young, 1993, p. 382). The pressure to conform to hegemonic masculine customs has been seen within football and other aggressive contact sports (Fields et al, 2007), such as hockey, wrestling, and rugby.

These issues create a culture of aggression within the world of collision and contact sports and make it difficult for athletes to separate the acceptable behavior 
expected of them on the field with unacceptable behavior off the field (Young, 1993). John Niland, a former Dallas Cowboy football player, explained how being expected to be violent in one aspect of his life, but not in others, was tough for him and his teammates: "We're paid to be violent...When the game's over, technically, it's to be turned off. But you can't...” (Messner, 2015, p. 447). With the lines of acceptable behavior blurred, aggressive and masculine conduct inflates the feelings of superiority that men have culturally learned to feel over women and some men (especially men in subordinate groups) that do not match the hegemonic masculine norms within American society (Walton, 2001).

When athletes conform to masculine traditions, those traditions become part of their identity (Hogg \& Reid, 2006). Identity could be defined as "who you are, the way you think about yourself, the way you are viewed by the world and the characteristics that define you," ("Identity," n/d, p. 1). The masculine gender role attached to American sports forms a salient athletic identity (Steinfeldt \& Steinfeldt, 2012), which is defined as "the degree to which an individual identifies with the athletic role" (Brewer, Van Raalte, \& Linder, 1993, p. 237). Although a strong athletic identity is not innately problematic, it can provide destructive outcomes when other aspects of the self are not explored. Recent research regarding masculinity socialization and athletic identity indicated that football players whom strongly identify as an athlete "also reported higher levels of conflict with societal gender role expectations and more negative attitudes toward help seeking” (Steinfeldt \& Steinfeldt, 2012). Further, the longer one is submerged into a certain culture, the more adapted to that lifestyle and behavior pattern they become (Gee \& 
Leith, 2007). In other words, their athletic identity becomes even more prominent, while other aspects of the self are neglected.

\section{Purpose of the Study}

Researchers have investigated how and why football players conform to masculine norms (Messner, 2015; Steinfeldt \& Steinfeldt, 2012; Young, 1993) and have considered how the normalization of aggression within certain sports often lead to violence against women (McCray, 2015; Murnen \& Kohlman, 2007). Little is known males' conformity to masculine norms and adaptation of an athletic identity among different types of sports (e.g., collision, contact, and non-contact). Therefore, the purpose of the current study is to retrospectively explore athletic identity and conformity to masculine norms amongst those who identify as male.

\section{Research Question(s)}

- Do male college students differ in terms of conformity to masculine norms depending upon type of sport they played in high school: collision, contact or non-contact?

- Do male college students differ in terms of athletic identity depending upon type of sport they played in high school: collision, contact or non-contact?

- What is the relationship between conformity to masculine norms and athletic identity?

Based on the literature, it is expected that those who played collision sport in high school will have the strongest conformity to masculine norms, while those who played contact sport will have the next strongest, and those who participated in non-contact sport will show the lowest levels of conformity to masculine norms. Further, those athletes with more salient athletic identities will show higher levels of conforming to hegemonic 
masculinity. More specifically, the level of conformity to masculine norms will depend the type of sport an athlete played due to the culture surrounding that sport and their adherence to an athletic identity.

\section{Importance of the Study}

This study contributes to the understanding of male college students' conformity to hegemonic masculine norms and their relationship to athletic identity. Previous literature suggests that hegemonic masculinity and American male sport culture contribute to off-field aggression and violence (Messner, 2015; Young, 1993). Addressing off-field violence committed by athletes is an issue of societal concern, and the overrepresentation of athletes as perpetrators of violence toward women is of particular concern to athletic departments and campus administrators. The results of this study will help coaches, sport psychologists, administrators and researchers better understand those who participated in and/or continue to participate in male athletics by providing a clearer picture of how athletes across a wide range and type of sport conform to hegemonic masculinity and adopt athletic identities. A more nuanced understanding of these psychological and sociological dimensions of male athletes has implications for coaching and athletic development, particularly with respect to addressing anti-social behavior and providing pro-social educational programming. 
Table 1.1 Operational Definitions

\begin{tabular}{|l|l|}
\hline Aggression & $\begin{array}{l}\text { The intentional harm, either physically or psychologically, toward } \\
\text { another living organism }\end{array}$ \\
\hline Violence & An extreme form of aggression, such as assault, rape, or murder \\
\hline Traditional Masculinity & $\begin{array}{l}\text { Includes concepts such as aggression, courage, dominance, respect, } \\
\text { honor, risk-taking }\end{array}$ \\
\hline Hegemonic Masculinity & $\begin{array}{l}\text { A framework for culturally ideal and socially dominant traits that } \\
\text { men seek to obtain; include concepts such as heterosexuality, } \\
\text { competitiveness, and aggressiveness }\end{array}$ \\
\hline Behavior & $\begin{array}{l}\text { Both the overt actions (publicly observable) and the covert actions } \\
\text { (subdermal experiences, like feelings and thoughts) of an individual }\end{array}$ \\
\hline Group Norms & $\begin{array}{l}\text { Regularities in attitudes and behavior that characterize a social } \\
\text { group and differentiate it from other social groups }\end{array}$ \\
\hline Athletic Identity & \begin{tabular}{l} 
The degree to which an individual identifies with the athletic role \\
\hline
\end{tabular} \\
\hline
\end{tabular}




\section{CHAPTER II: LITERATURE REVIEW}

The current study is focused on exploring how sporting culture affects athletes on and off the field by investigating male college students sporting experiences from high school, specifically focusing on conformity to masculinity and the role of athletic identity. Although sports are recognized and celebrated for the positive aspects (e.g., “competition, fair play, self-restraint, and achievement” (Kreager, 2007, p. 705), this study will contribute to a body of literature concerned with the less desirable aspects of sport, in particular, specific traits associated with hegemonic masculinity. This line of research is important for coaches and administrators, as well as parents, who may get a better understanding of athletes' behaviors in different types of sports. The following sections examine the literature regarding the social learning and social identity theories, how certain sports might attract more aggressive athletes, the culture surrounding contact sports, the socialization of aggression, the normalization of violence, and domestic violence.

\section{Social Learning \& Social Identity Theories}

The cyclical behavior seen in the world of American male collision and contact sports can be explained through the lens of the social learning and social identity theories. The social learning theory provides logic for how and why human beings learn to behave in the manner they do (Thyer \& Myers, 1998), while the social identity theory explains how individuals identify with themselves and the societal groups in which they belong to (Hogg \& Reid, 2006). 
Behavioral psychologist B. F. Skinner (1957) determined that:

Men act upon the world, and change it, and are changed in turn by the consequences of their action... When appropriate behavior [deemed so by society] is established, its consequences work through similar processes to keep it in force. If by chance the environment changes, old forms of behavior disappear, while new consequences build new forms, (p. 1).

Behavior can be defined as both the overt actions (publicly observable) and the covert actions (internal experiences, like feelings and thoughts) of an individual (Thyer \& Myers, 1998). Individuals learn how to behave through a type of "trial and error" procedure. Respondent conditioning is the type of social learning by which humans and animals alike learn how to acclimatize to their environment. After being subjected to a certain stimulus multiple times, that stimulus begins to elicit a specific response becoming what is called a conditioned stimulus, making the person's reaction a conditioned response (Thyer \& Myers, 1998). Therefore, the individual learned to respond to their new environment.

"Respondent conditioning focuses on how environmental events or stimuli occurring before a behavior come to automatically elicit relatively simple reflexive acts," whereas operant conditioning concentrates on how consequences that come after a behavior influences the probability of that behavior reoccurring in the future (Thyer \& Myers, 1998, p. 38). This latter form of conditioning focuses more on the reaction from others or the environment and its role in influencing the individual to repeat or suppress that behavior. These reactions can occur as positive reinforcement (something pleasant is given), e.g., coach giving a high five after scoring a goal; negative reinforcement 
(something unpleasant is taken away), e.g., the label of last place being taken away after a big win; positive punishment (something unpleasant is given), e.g., having to run laps due to a loss; or negative punishment (something pleasant is taken away), e.g., a player's starting position being taken away due to poor performance. It is important to remember that in social learning theory, reinforcement is a desirable consequence, while punishment is an undesirable consequence, regardless of the positive or negative inflection associated with them (Thyer \& Myers, 1998). Overall, operant conditioning describes how humans learn from the consequences of their behaviors and adjust future actions accordingly.

According to the social learning theory, behaviors can be shaped through selective reinforcement to obtain desired behaviors, or they can be discouraged through the discontinuation of reinforcing consequences (i.e., operant extinction) (Thyer \& Myers, 1998). Coaches, teammates, parents, sporting organizations, media, etc. play a part in determining which behaviors are reinforced - leading to repetition, and which are not leading to extinction. In other words, athletes are influenced by the cultural values placed on certain behaviors in connection with their chosen sport (Gee \& Leith, 2007; Messner, 2015; Young, 1993).

In a sport setting, players' behavior may stem from following rules or observing others. Rule-governed behaviors are instructions that are given, obeyed, and then reinforced within a certain setting (e.g., the football field). The presentation and reinforcement of rule-governed behavior comes initially from the caregiver (e.g., a coach) and then naturally recurs after continuous reinforcement (Thyer \& Myers, 1998). A coach might demand his players shake hands with opponents after the game. The players learn 
their coach's expectations and begin to naturally move toward shaking hands with opponents once the game ends. In sports, coaches and organizations influence rulegoverned behaviors, whereas observational learning occurs most often with peers. Observational learning is how humans learn through the imitation of others. When an imitated behavior is reinforced, the behavior becomes strengthened (Thyer \& Myers, 1998). An athlete might observe a teammate complete an aggressive tackle and then earn a "nice job!" from a coach. That athlete might imitate the aggressive behavior and, if he/she earns a similar comment (or another affirmative consequence) from the coach, that behavior is reinforced.

Social identity theory focuses on the conditions that stimulate "different types of intergroup behavior - for example, conflict, cooperation, social change, and social stasis" (Hogg \& Reid, 2006, p. 9). Certain socially accepted behavioral traits regulate how people act in certain situations or within specific groups. People within groups transform how they feel and behave in order to generate feelings of belonging by conforming to the group norms constructed by others within the unit. Group norms are defined as "regularities in attitudes and behavior that characterize a social group and differentiate it from other social groups" (Hogg \& Reid, 2006, p. 7). The norms of a particular group depersonalize the individual and the group begins to expect each individual to perform accordingly to the group's norms (Hogg \& Reid, 2006). In a sport context, a group can be as small as a single team or as large as entire organizations, such as the National Football League.

In conclusion, the social learning and social identity theories help researchers to understand how and why athletes learn to behave from each other, their coaches, and the 
sport itself. As athletes grow through different levels of competition in a particular sport, e.g., youth to collegiate, and possibly to professional, they play for many different teams and come into contact with many different coaches, teammates and organizations. The concepts underlying the theories detailed above suggest that athletes learn the behaviors that are most valuable to their sport and that those behaviors are reinforced through respondent conditioning, operant conditioning, shaping, and group norms, thereby creating a culture that is sport-specific.

\section{Violent Sports Attract Violent Athletes}

Student-athletes have been found to consistently have high numbers of reports of sexual and other aggressive assaults against women on college campuses. McCray (2015) brought attention to the need for more empirical and qualitative data to further understand how or why athletes commit violence against women. McCray explains, one must first recognize how the culture surrounding student-athletes affects their behavior in order to understand why certain behaviors (e.g., violence, sexual assault, etc.) are common amongst this population.

To build on the research regarding violent behavior Kreager (2007) examined information submitted by 6,397 adolescent boys from 120 different schools. He investigated if getting into serious fights was related to a number of independent variables, such as type of sport, prior fighting experiences, number of friends in certain sports, minor delinquencies, and family status/structure. Kreager determined that football players and wrestlers had the strongest positive association to male violence, while tennis players had the strongest negative relationship with male violence. Football and wrestling are two sports with high contact and are known for being historically almost exclusively 
male, whereas tennis has no physical contact and more gender-equitable participation. Kreager's results provide a strong example of how boys that were more inclined to get into a fight were more inclined to play aggressive, high-contact sports.

Investigating males and females in a sport setting helped researchers better grasp why males act out more violently than females. Moesch, Birrer, and Seiler (2010) surveyed 795 boys and 869 girls between 12 and 18 years old on physical and psychological violence by utilizing questionnaires about sport engagement, violent behavior and cognition, self-concept, wellbeing, and stress perception. After analyzing the data, the researchers put the adolescents into five categories based on relevant themes within their answers: adolescents at risk, non-violent adolescents, psychological harassers, violence supporters, and violent adolescents. Of pertinence to the present study, psychological harassers spent the most time playing sports and consisted of far more males than females. Violent adolescents were most likely to participate in team contact sports as compared to the non-violent adolescents. Moreover, there was an overrepresentation of males in the violent adolescents group, which the authors posit could be due to males being more likely to participate in aggressive contact sports.

Not only are contact sports appealing to those who already display aggressive behaviors, but participating in contact sports encourages aggression (Lemieux, McKelvie, \& Stout, 2002). In other words, "aggression breeds aggression" (p. 43). To understand how the type of sport and physical size of an athlete affects levels of aggressive behavior, Lemieux et al (2002) gave the Aggression Questionnaire to four groups of college-aged males. One group was made up of varsity-level contact sport athletes, while the second group included varsity-level non-contact sport athletes. Group Three consisted of college- 
aged males who physically matched group one in height and weight, and Group Four was comprised of college-aged males who were physically comparable to the non-contact athletes in Group Two. The non-contact athletes and their physically matched nonathletes were generally smaller in size than the contact-athletes and their group of physically matched non-athletes. Additionally, the physically larger participants reported higher hostile aggression levels. When examining the two athletic groups in this study, it appears that contact sports attract larger and more hostile college-aged participants than non-contact sports (Lemieux et al, 2002).

\section{Understanding the Culture of American Contact Sports}

This proclivity of aggressive young men to participate in contact sports is supplemented by an ongoing socialization of athletes once they become a part of the American sporting culture. Gee and Leith (2007) examined the official game reports from the first quarter of the 2003-2004 National Hockey League (NHL) regular season to explore possible differences in European and North American hockey players' violent behavior. The researchers collected data on each player's position, experience in the NHL, birthplace, whether a game was at the home rink or away, and all information regarding penalty infractions. Evidence showed that North American players were more likely to commit aggressive penalties than the European players. European rookies committed the least amount of aggressive penalties and the European veterans committed more penalties toward the end of the researchers' observations than at the beginning of the season with was attributed to the accumulated socialization of violence and aggression on the ice as the season progressed. Another interesting finding was that North American hockey players perceived that coaches and scouts demanded them to display 
aggressive behavior. The cultural difference seen in this study challenged the assumption that aggressive behaviors are an inherent part of the game of hockey (a collision sport) when in fact it is more likely due to the culture surrounding specific organizations (Gee \& Leith, 2007).

\section{Socialization and Aggression}

For more knowledge on the masculine and aggressive socialization process of sports, one must learn the factors that facilitate it. Pappas et al (2004) identified three groups of influences on the aggressive behaviors of athletes: 1) the athletes' coaches, teammates, and families; 2) the structure of their specific sport and the rules that govern them; and 3) the general attitude surrounding that sport by the fans, media, and the law. The researchers interviewed five former competitive hockey players who described their overall experience playing organized hockey, and in particular, playing a sport that encouraged aggression. The players identified the socialization within the sport of hockey as promoting violence both on and off the ice. Masculine expression was said to be a reason for behaving aggressively, as well as a desire to earn competitive success. Moreover, athletes perceived their coaches as promoting aggression and to win at all costs. Athletes' destructive behaviors were perceived as expected by coaches, teammates, sporting organizations and fans. In addition to the promoting of aggression on the ice, these behaviors promoted a culture of negative male peer influences that often objectified women (Guivernau \& Duda, 2002).

Coaches are an especially important part of the socialization process (Guivernau \& Duda, 2002) and many athletes' perceptions of their coaches influence their on-field behavior (Gee \& Leith, 2007; Pappas et al, 2004). Guivernau and Duda (2002) 
investigated if the aggressive tendencies of youth soccer players are influenced by significant others (e.g., parents, coaches, teammates) and whether or not there is a predominant figure that most affects player aggressiveness. The authors surveyed 194 male and female youth soccer players between the ages of 13 and 19 years old. The participants were asked about their significant influences and their perceived ideas of peer cheating, peer aggression, coach cheating, coach aggression, mother/father cheating, and mother/father aggression. Perceptions of their significant others' beliefs and values influenced these young athletes greatly; however, they pointed to the coach as the single most influential person on young athletes' moral decision making. If their coach is proaggression, the athlete develops the idea that aggressive behavior is appropriate at a young age. Guivernau \& Duda (2002) concluded that this pattern of coach-dependent decision-making could carry over into their collegiate and professional careers.

\section{Normalization of Violence \& Acceptance of Domestic Violence}

The cultural expectation for men to use their bodies as a weapon in contact sports creates a standard that aggression is a valued trait (McDonald, 1999; Messner, 2015; Young, 1993). These ideals are reinforced when coaches, teammates, and fans applaud their aggression. This expression of male power produces a hegemonic ideal that makes other groups of people (e.g., women, minorities) subordinate (Young, 1993). Further, it fosters athletes to feel "a sense of entitlement, sexual access, and power over women" (McDonald, 1999, p. 111).

American culture praises male athletes for their on-the-field prestige and then makes excuses for any violence committed off the field (McDonald, 1999). While it is common for the public to ignore acts of violence committed in the sport setting because it 
is considered a regulated part of the game, McDonald (1999) advocated for some degree of change in behavior before the team, the media, and the fans forgive that athlete for committing sometimes-heinous acts of abuse. Fields and colleagues (2007) reviewed the literature on sports-related violence and found if an athlete's frustration evolves into anger and the setting allowed for violent behavior (e.g., sporting arena, in a bar setting, or behind closed doors at home), a fight might break out as a parade of athletes' masculinity, strength, and superiority. This attitude contributes to the ongoing cycle of celebrating violence in aggressive sports, allowing athletes to perceive violence and assaults off the field as an acceptable part of being masculine (Fields et al, 2007; McDonald, 1999; Messner, 2015; Young, 1993). By accepting domestic violence as a private matter to be sorted out between husband and wife, the media and fans further promote the acceptance of this behavior (Walton, 2001). For example, the five hockey players interviewed by Pappas et al (2004) "tended to differentiate between general physical violence and sexual aggression or violence, seeing the latter as less serious and more understandable than general physical violence" (p. 309).

The attention that violence gets from the media and sports fans stems from the social systems set up within American culture (Fields et al, 2007). Walton (2001) explored how the victim's social status effects how society portrays violent assaults of athletes and coaches. She investigated the attack of Golden State Warriors' coach, P.J. Carlesimo, by one of his players, Latrell Sprewell, which gained a lot of media attention because this incident featured a black employee who assaulted his white boss. This type of public violence threatens social order and power dynamics. However, when violence occurs in the private home of athletes and coaches, it goes unnoticed because it is deemed 
culturally insignificant. In other words, domestic violence in a private home fits the hegemonic style of American culture and is not considered newsworthy. The view that women are low in value and the lack of stigmatization of men for being violent creates a level of acceptance for violence against women (Walton, 2001).

Sports teams are not the singular male-only social group to be studied with respect to conformity to masculine norms. For instance, Murnen \& Kohlman (2007) completed a meta-analysis of 29 studies focused on fraternity members, college athletes, and sexual aggression (e.g., acceptance of rape myth, self-reported sexual aggression, and being hyper-masculine). It was determined that both groups were linked with the sexual objectification of women and hypermasculine mindsets, with hyper-masculinity being the "strongest variable to differentiate between athletes and fraternity members and the comparison groups" (p. 153). Athletes and fraternity members reported higher numbers than the neutral groups, but the findings indicated that athletic participation revealed larger effect sizes than fraternity members in each form of sexual aggression and hypermasculinity listed above. The authors determined that athletes had higher scores due to the fact that collegiate male athletes were likely socialized into a hypermasculine culture longer (i.e., youth sports) than those in fraternities (Murnen \& Kohlman, 2007).

The extent to which athletes adopt the hegemonic masculinity associated with sport is not well understood and is an area to which the current study will contribute. Steinfeldt \& Steinfeldt (2012) addressed this question by looking at measures of athlete identity and conformity to masculine norms amongst college football players. Five hundred and twenty-three college football players from eight different universities completed the Athletic Identity Management Scale (AIMS) and the Conformity to 
Masculine Norms Inventory-46 (CMNI-46). The CMNI-46 is comprised of nine subscales: winning, emotional control, risk-taking, violence, power over women, playboy, self-reliance, primacy of work, and heterosexual self-presentation. Results showed that athletes' conformity to masculine norms did not differ based on their level of play (Division I, II, or III). However, defensive players reported higher levels of conformity to the heterosexual self-presentation masculine norm as compared to offensive players, and senior defensive linebackers had conformed the most to the violence norm (i.e., they perceived themselves to be highly violent). Defensive players are usually taught to objectify the opposing team in order to make aggressive, and sometimes harmful, tackles, so their heightened conformity to violence makes sense. Another interesting aspect of this study was that the heterosexual self-presentation norm was significantly affected by multiple factors, including year in school, position on the field, and a stronger athletic identity. In other words, this ideal of heterosexual self-presentation is foundational to a homophobic atmosphere within the culture of football. This homophobic norm correlates to the need to feel masculine and have power over women and homosexuals (Steinfeldt \& Steinfeldt, 2012).

Although aggressive athletes tend to participate in the more aggressive contact sports (Kreager, 2007; Lemieux et al, 2002; Moesch et al, 2010), it is important to note that not all male athletes are linked to initiating altercations off the field. In order to understand the motivation for aggressive behaviors off the field, Grange and Kerr (2011) examined verbal aggression on the field and physical aggression off the field. They interviewed eight elite male Australian football players between the ages of 25 and 34 who were known for being aggressive athletes. Analysis of the interviews resulted in 
themes pertaining to perception of aggressive acts, alcohol's role in aggressive behavior, how they responded in social settings, and perceptions of the physical hazards of aggression both on and off the field. Grange and Kerr found that athletes tend to get involved in male-to-male violence in order to generate feelings of excitement and dominance over other social groups. Interestingly, the athletes in this study claimed they usually did not start the altercations they have been involved in. The participants explained that it usually started with a bump or challenge from another person in a bar. An interview does have the limitation of the participant wanting his or her answers to come off as socially desirable. However, this study demonstrates that one cannot simply rely on the fact that a person is a contact-sport athlete to determine who might or might not conform to the masculine norms (Grange \& Kerr, 2011). Therefore, it is important to examine athletes from all sports to gain more insight as to how and why athletes conform to masculine norms, especially ones such as violence and power over women.

The review of literature on this topic includes many different reasons and ways that male athletes' aggression and masculinity on and off the field is detrimental to the moral future of the culture of American sports. Coaches and teammates promote aggressive behaviors on the field that inevitably transfer into their off-the-field behaviors (Guivernau \& Duda, 2002; Marasescu, 2014; Messner, 2015; Pappas et al, 2004). These behaviors are further reinforced by the lack of penalization of violence by sporting organizations, as well as media coverage downplaying violent acts against women (Fields et al, 2007; McDonald, 1999; Pappas et al, 2004; Walton, 2001). Although research has focused on masculine norms' influence over the aggression of athletes, less is known about male athletes representing different types of sports and the extent to which these 
athletes conform to certain masculine tendencies. Overall, the basic goal of the current study was to retrospectively explore masculinity and identity in college males for the purpose of better understand which sports or type of sport promote hegemonic values such as violence and power over women. Practical implications from the results may include interventions for athletes to separate behaviors appropriate on the field from those inappropriate off the field. 


\section{CHAPTER III: METHODS}

\section{Participants}

Male students $(n=94)$ at a university in the Pacific northwestern region of the United States were recruited from several undergraduate kinesiology courses to take a survey about their past high school sport experience. The participants were in their early $20 \mathrm{~s}(\mathrm{M}=22 \mathrm{yr}, \mathrm{SD}=4.68)$ and had been in college for an average of two years $(\mathrm{SD}=$ 1.25). The athletes in this sample identified as White (74.5\%), African American (7.4\%), Hispanic/Latino(a) (5.3\%), American Indian (2.1\%), Native American/Islander (2.1\%), Asian $(1.1 \%)$, other $(6.4 \%)$. The students were also asked to comment on their parent/guardians' highest level of education completed.

\section{Measures}

\section{$\underline{\text { Demographics }}$}

In addition to providing demographic information concerning age, year in college, race, and parental level of educational acquisition, participants also responded to questions asking them to identify the type of sport most excelled at, the number of years spent playing the sport most excelled at, the position played in the sport most excelled at, and whether or not the participant was currently playing a collegiate varsity sport. The students also reported sport participation during their high school years for their school, recreationally, and/or for a club team (see Appendix A for the complete list of background questions). Neither participant names nor names of high schools they attended were collected. 


\section{Conformity to Masculine Norms}

Mahalik and colleagues (2003) created the Conformity to Masculine Norms Inventory (CMNI) in order to examine adaptive and maladaptive associations to men's adherence to the masculine norms established as valuable in American society. The psychologists reviewed past literature to identify hegemonic masculine norms and discovered that, "the expectations of masculinity as constructed by Caucasian, middleand upper-class heterosexuals should affect members of that group and every other male in U.S. society who is held up to those standards" (p. 5). The authors established 11 subscales over a trial of five studies, but later discarded two of the subscales. Parent \& Moradi (2009) revised the CMNI (originally 94 items) to a shorter version (CMNI-46), using the nine retained subscales: winning, emotional control, risk-taking, violence, power over women, playboy, self-reliance, primacy of work, and heterosexual selfpresentation.

The gender norms associated with the 46 statements that make up the nine subscales of the CMNI-46 are briefly described below using sample questions from the instrument (Parent \& Moradi, 2009). The category of Winning includes six items; for example, "In general, I will do anything to win." Emotional Control regards six remarks such as, "I hate it when people ask me to talk about my feelings." Risk-Taking is measured by five statements like, "I enjoy taking risks." Six comments such as, "Sometimes violent action is necessary," measure the category of Violence. The fifth category, Power Over Women, includes four statements like, "In general, I control the women in my life." Playboy (i.e., being sexually promiscuous) regards four remarks such as, "If I could, I would frequently change sexual partners." The seventh set of statements 
measures Self-Reliance, and uses five comments like, "I hate asking for help." Primacy of Work regards the participants work ethic and includes four statements like, "My work is the most important part of my life." Finally, the last category of Heterosexual SelfPresentation includes six statements such as, "I would be furious if someone thought I was gay." (See Appendix B for a complete list of questions). Participants indicated their level of agreement with each item, as described below, and these responses reflect their attitudes and beliefs about the masculine norms associated with each CMNI-46 subscale grouping.

Similar to Mahalik et al (2003), Parent and Moradi (2009)'s version of the survey used a 4-point Likert scale for each of the items. The participants were asked to answer using one of the following four options: "strongly disagree" (coded as 0), "disagree" (1), "agree" (2), and "strongly agree" (3). Some of the statements on the survey were reversecoded. After the participants completed the survey, the researcher totaled their cumulative score, which indicated how much the athletes' beliefs and behaviors reflect the conformity to traditional masculine norms. Further, the individual subscales were averaged to determine a single score for each subscale. Mahalik et al. (2003) and Parent \& Moradi (2009) found internal reliability for the subscales ranged from 0.76 to 0.91 . In the current study, the internal reliability were all acceptable with alpha levels all exceeding 0.70 (Nunnally \& Bernstein, 1994). See Table 4.3a for the alpha levels for the CMNI-46 subscales from three different studies.

\section{$\underline{\text { Athletic Identity }}$}

The Athletic Identity Measurement Scale (AIMS; Brewer et al, 1993) is the most frequently used inventory for athletic identity and consists of ten items "designed to 
reflect the strength and exclusivity of identification with the athlete role" (Brewer \& Cornelius, 2001, p. 103). In a more recent study, three of the original ten items were removed due to meager performance in a factor analysis (Brewer \& Cornelius, 2001). The remaining seven items comprise three factors: social identity, exclusivity, and negative affectivity. Social identity was measured using three statements such as, "Most of my friends are athletes." Exclusivity was measured with two statements like, "Sport is the most important part of my life." Finally, the athletes' negative affectivity was revealed using two statements such as, "I feel bad about myself when I do poorly in sport." This survey employs a 7-point Likert scale. In this case, participants marked one for "strongly disagree," seven for "strongly agree," or any number between depending on their inclinations regarding the given statement, as presented by the directions of the AIMs measure. Previous studies showed an average of the subscales' internal consistency (81, Brewer \& Cornelius, 2001; 76, Visek, Watson, Hurst, Maxwell, \& Harris, 2010) for the AIMS as well. Table $4.3 \mathrm{~b}$ provides the internal reliability for the three subscales from the current study.

Although Nunnally and Bernstein (1994) set a criterion score of .70 for reliability, other psychometricians, such as Cortina (1993) established that alpha values are dependent of the total number of items within a particular scale. In the current study, negative affectivity was comprised of only two items, which allows for vulnerability to internal consistency. The lower internal consistency of the negative affectivity subscale is a possible limitation of this study. However, due to the importance of the negative affectivity subscale and given that this is an exploratory (descriptively-based) study, the decision was made to retain this subscale in the main study analyses. In these situations, 
scholars such as Schmitt (1996), proposed that alpha values as low as .50 may be adequate for use in behavioral research.

\section{Procedures}

This study was approved by the University's Office of Research Compliance Human Subjects Review Board. The researcher contacted several professors in the Department of Kinesiology at a University in the Pacific Northwest via email to request the recruitment of their students and to ascertain a convenient time and date to come to their classroom and survey their undergraduate students, with the presumption that Kinesiology students have sporting experience. On the scheduled days and times, the researcher went to the classroom and asked the instructor to step out before briefly introducing the purpose of the study to the students. The survey was then distributed to every student and the students who identified as male were asked to participate in the 15minute survey. The first page of the survey consisted of an informed consent page (see Appendix D). The participants were told that if they read through the consent page and chose to continue with the survey they were providing the researcher with consent, as no names were being recorded. The data was only accessible by the researcher and thesis committee members.

\section{Data Analysis}

First, descriptive statistics for all study variables were calculated, including the means, standard deviations, and the ranges for the CMNI and AIMS subscales. Participant responses for the type of sport excelled at and type of sport played during high school were categorized as collision, contact or non-contact. Previous literature has classified some sports as high or low contact. For example, football, basketball, rugby, 
and soccer are identified as high contact sports, while baseball, volleyball, track, and golf counted as low contact sports (Huang, Cherek, \& Lane, 1999; Lemieux et al, 2002). The additional refinement of categories to include collision sports was based on the National Collegiate Athletic Association's (NCAA) assessment of impact expectations with respect to injuries. The NCAA takes into account collisions (within contact sports), thereby distinguishing and identifying another category of sport (NCAA, 2014). Sports such as boxing, gymnastics, cheerleading, cross fit, power lifting, motocross, competitive paintball, and surfing were categorized by the author according to the previously mentioned definitions of collision, contact, and non-contact sports.

Second, to answer the research questions regarding the connection between the type of sport males excelled at most during their years in high school and the CMNI-46 and the AIMS, two Multivariate Analysis of Variances were conducted. For the first analysis, the independent variable included the type of sport played (i.e., collision, contact, non-contact), while the dependent variables consisted of the nine subscales included in the CMNI-46 (i.e., winning, emotional control, risk-taking, violence, playboy, self-reliance, power over women, primacy of work, and heterosexual self-preservation). For the second MANOVA, the independent variable was the type of sport played (i.e., collision, contact, non-contact), while the dependent variables consisted of the three subscales included in the AIMS (i.e., social identity, exclusivity, and negative affectivity). If the MANOVA was significant, a follow-up univariate ANOVA was conducted. Finally, to explore the relationship between the CMNI and the AIMS, we conducted a bivariate correlation for all of the subscales in the two measures. 


\section{CHAPTER IV: RESULTS}

The purpose of this study was to explore whether conformity to masculine norms and level of athletic identity were related to experience participating in specific sports or categories of sport (e.g., collision, contact, non-contact) amongst college males. The study results are organized to first show the high school sport participation history of the participants, followed by the descriptive statistics of the subscales for the CMNI-46 and the AIMS instruments, then the results of the MANOVAs, and, finally, correlations between these two instruments.

Many of the participants $(n=94)$ played multiple sports in high school, while some did not partake in any sporting activities during their years in high school (zero sports, $n=4$; one sport, $n=12$; two sports, $n=30$; three sports,$+ n=48$ ). Of the 90 participants that responded to this question about sport participation, more than half $(51.06 \%)$ reported playing three sports or more. One student did not answer whether he played sports in high school or not. Figure 4.1 reflects which sport these participants excelled at best. Forty participants excelled most at collisions sports, 30 participants excelled most at contact sports, 20 participants excelled most at non-contact sports, while three participants did not specify a certain type of sport they excelled most at during high school. Table 4.2 organizes the sports reported by participants into collision, contact, and non-contact, and shows the number of participants that identified each sport. 
Table 4.1 Type of Sport Excelled At

\begin{tabular}{|l|l|l|l|}
\hline Collision & Contact & Non-Contact & No Response \\
\hline Football, $n=18$ & Basketball, $n=11$ & Track and Field, $n=10$ & $N=3$ \\
\hline Wrestling, $n=8$ & Soccer, $n=10$ & Cross Country, $n=6$ & \\
\hline Lacrosse, $n=6$ & Baseball, $n=9$ & Golf, $n=2$ & \\
\hline Hockey, $n=6$ & & Gymnastics, $n=1$ & \\
\hline Rugby, $n=3$ & & Motocross, $n=1$ & \\
\hline Total: $\mathbf{4 1}$ & Total: $\mathbf{3 0}$ & Total: 20 & Total: 3 \\
\hline
\end{tabular}

Table 4.2 Sports Played During High School Years

\begin{tabular}{|l|l|l|}
\hline Collision & Contact & Non-Contact \\
\hline Football, $n=53$ & Basketball, $n=42$ & Track and Field, $n=35$ \\
\hline Lacrosse, $n=8$ & Soccer, $n=22$ & Cross Country, $n=11$ \\
\hline Hockey, $n=8$ & Baseball, $n=20$ & Golf, $n=4$ \\
\hline Wrestling, $n=5$ & Water Polo, $n=1$ & Tennis, $n=4$ \\
\hline Rugby, $n=5$ & & Volleyball, $n=3$ \\
\hline Boxing, $n=1$ & & Gymnastics, $n=2$ \\
\hline & & Cheerleading, $n=2$ \\
\hline & & Cross Fit, $n=1$ \\
\hline
\end{tabular}




\begin{tabular}{|l|l|l|}
\hline & & Power Lifting, $n=1$ \\
\hline & & Motocross, $n=1$ \\
\hline & & Competitive Paintball, $n=1$ \\
\hline & & Surfing, $n=1$ \\
\hline
\end{tabular}

The means, standard deviations, and alphas levels were calculated for each of the subscales in the CMNI and the AIMS (See Table 4.3a and Table 4.3b). On the whole, the sample showed high means for winning $(M=1.94 ; S D=0.54)$, violence $(M=1.83 ; S D=$ $0.69)$, and risk taking $(M=1.64 ; S D=0.38)$ for the CMNI subscales, and low on power over women $(M=0.55 ; S D=0.45)$ and playboy $(M=0.89 ; S D=0.68)$. As for the AIMS schedule, the sample showed the highest mean for social identity $(M=5.39 ; S D=1.13)$ and the lowest mean was for exclusivity $(M=3.49 ; S D=1.48)$. This indicates that the participants, in general, tended to highly identify with the winning, violence, risk-taking, and social identity subscales. Conversely, they identified least with the power over women, playboy, and exclusivity subscales. 
Table 4.3a Means and Standard Deviations for CMNI Subscales

\begin{tabular}{|l|l|l|l|l|l|}
\hline Variable Name & $M$ & $S D$ & Alpha & $\begin{array}{l}\text { Range of } \\
\text { Scores }\end{array}$ & $\begin{array}{l}\text { Possible } \\
\text { Range }\end{array}$ \\
\hline Winning (CMNI-46) & 1.93 & .54 & .81 & $.50-3.00$ & $.00-3.00$ \\
\hline Violence (CMNI-46) & 1.83 & .69 & .88 & $.00-3.00$ & $.00-3.00$ \\
\hline Risk Taking (CMNI-46) & 1.64 & .38 & .39 & $.40-2.40$ & $.00-3.00$ \\
\hline Emotional Control (CMNI-46) & 1.43 & .59 & .86 & $.00-2.83$ & $.00-3.00$ \\
\hline $\begin{array}{l}\text { Heterosexual Self-Preservation } \\
\text { (CMNI-46) }\end{array}$ & 1.35 & .80 & .90 & $.00-2.83$ & $.00-3.00$ \\
\hline Primacy of Work (CMNI-46) & 1.33 & .65 & .77 & $.00-2.75$ & $.00-3.00$ \\
\hline Self-Reliance (CMNI-46) & 1.19 & .63 & .87 & $.00-2.60$ & $.00-3.00$ \\
\hline Playboy (CMNI-46) & .89 & .68 & .72 & $.00-3.00$ & $.00-3.00$ \\
\hline Power Over Women (CMNI-46) & .55 & .45 & .70 & $.00-2.25$ & $.00-3.00$ \\
\hline
\end{tabular}

Table 4.3b Means and Standard Deviations for AIMS Subscales

\begin{tabular}{|l|l|l|l|l|l|}
\hline Variable Name & $M$ & $S D$ & Alpha & $\begin{array}{l}\text { Range of } \\
\text { Scores }\end{array}$ & $\begin{array}{l}\text { Possible } \\
\text { Range }\end{array}$ \\
\hline Social Identity (AIMS) & 5.39 & 1.13 & .77 & $2.00-7.00$ & $1.00-7.00$ \\
\hline Negative Affectivity (AIMS) & 4.99 & 1.55 & .69 & $1.00-7.00$ & $1.00-7.00$ \\
\hline Exclusivity (AIMS) & 3.49 & 1.48 & .82 & $1.00-7.00$ & $1.00-7.00$ \\
\hline
\end{tabular}


To test whether the type of sport that participants indicated that they excelled best at influenced their attitudes or behavior regarding masculinity, a MANOVA was conducted with sport type (collision, contact, and non-contact) serving as the independent variables and the subscales of the CMNI serving as the dependent variables. The MANOVA was significant for the type of sport the participants excelled at, $F=1.86, d f=$ $1.34, p<.05$, showing that collision sport athletes were more violent than contact and non-contact sport athletes. Upon investigation of the univariate ANOVAs, only the subscale violence was significant, $F=4.99, d f=2, p<.01$. Tukey post hoc tests indicated that the collision group and the contact group significantly differed, with the collision group having higher acceptance of violence than the contact group $(M=.54, d f=.17, p=$ 0.008.) The non-contact group did not significantly differ from the other two groups and no other differences existed in relation to sport most excelled at and the subscales of the CMNI.

A second MANOVA was conducted to test if the type of sport participants excelled at influenced their athletic identity. A MANOVA was conducted with sport type (collision, contact, non-contact) serving as the independent variables and the subscales of the AIMS (social identity, exclusivity, negative affectivity) serving as the dependent variables. The MANOVA was not statistically significant for the type of sport the participants excelled at, $F=1.17, d f=172.00, p>.05$. Since the MANOVA was not significant, follow up univariate ANOVAs were not conducted. This means that the three groups (i.e., collision, contact, and non-contact sports) did not significantly differ in their athletic identity. 
The researchers then examined how the CMNI-46 subscales were related to each other. The winning, violence, playboy, and heterosexual self-presentation subscales were all positively correlated to three other CMNI-46 subscales (see Table 4.4). One subscale did stand out from the others. Primacy of work had a significant negative correlation between and violence $(r=-.31, p=<.01)$, and heterosexual self-presentation $(r=-.22, p$ $=<.05)$.

Similarly, the AIMS subscales were analyzed to determine how they related to each other. The three AIMS subscales (social identity, exclusivity, and negative affectivity) were all significantly positively correlated to one another, ranging from .42 to .47. There was a positive correlation between social identity and exclusivity, $r=.42, p=$ $<.01$. There was a positive correlation between social identity and negative affectivity $(r$ $=.47, p=<.01)$. Finally, there was a positive correlation between exclusivity and negative affectivity, $r=.44, p=<.01$. See Table 4.4 for the correlations between all of the subscales.

To explore the relationship between the CMNI-46 and the AIMS for the total sample, a bivariate correlation was conducted. The three AIMS subscales were significantly correlated to many of the CMNI subscales as well. Social identity was significantly correlated to the following CMNI subscales: winning $(r=.32, p=<.01)$, violence $(r=.27, p=<.05)$, and heterosexual self-presentation $(r=.32, p=<.01)$. Exclusivity was significantly correlated to emotional control $(r=.30, p=<.01)$ and selfreliance $(r=.32, p=<.05)$. Finally, negative affectivity was significantly correlated to the same subscales as social identity: winning $(r=.37, p=<.01)$, violence $(r=.21, p=<$ $.05)$, and heterosexual self-presentation $(r=.21, p=<.05)$. 
Table 4.4 Correlations

\begin{tabular}{|c|c|c|c|c|c|c|c|c|c|c|c|c|}
\hline & 1. & 2. & 3. & 4. & 5. & 6. & 7. & 8. & 9. & 10. & 11. & 12. \\
\hline 1. CMNI Winning & & & & & & e & & & & & & \\
\hline 2. CMNI Emotional Control & .04 & & & & & & & & & & & \\
\hline 3. CMNI Risk-Taking & .13 & .03 & & & & & & & & & & \\
\hline 4. CMNI Violence & $.36^{* *}$ & .09 & $.36^{* *}$ & & & & & & & & & \\
\hline 5. CMNI Power Over Women & .16 & .10 & -.04 & .12 & & & & & & & & \\
\hline 6. CMNI Playboy & $.30 * *$ & .11 & $.26^{*}$ & $.21^{*}$ & -.18 & & & & & & & \\
\hline 7. CMNI Self-Reliance & .08 & $.37 * *$ & .09 & .13 & .20 & .01 & & & & & & \\
\hline 8. CMNI Primacy of Work & -.06 & .08 & -.18 & $-.31 * *$ & -.13 & .04 & -.02 & & & & & \\
\hline 9. CMNI Heterosexual Self-Presentation & $.27 * *$ & .08 & .01 & $.34 * *$ & $.48 * *$ & -.07 & .15 & $-.22 *$ & & & & \\
\hline 10. AIMS Social Identity & $.32 * *$ & .08 & .06 & $.27 *$ & .20 & -.04 & -.10 & .17 & .32 & & & \\
\hline 11. AIMS Exclusivity & .15 & $.30 * *$ & -.03 & .02 & .20 & .11 & $.21^{*}$ & .16 & .17 & $.42 * *$ & & \\
\hline 12. AIMS Negative Affectivity & $.36^{* *}$ & .19 & .05 & $.21 *$ & .11 & .16 & .14 & .15 & $.21 *$ & $.47^{* *}$ & $.44^{* *}$ & \\
\hline
\end{tabular}

Note: $*=\mathrm{p}<.05, * * \mathrm{p}<.01$ 


\section{CHAPTER V: DISCUSSION}

The purpose of this study was to examine the similarities and differences in the conformity to masculine norms in college male students based on their sport participation experience in high school. It was expected that those who played collision sports during their high school years would have the strongest conformity to masculine norms. Additionally, it was proposed that those participants with more salient athletic identities would have higher levels of conforming to hegemonic masculinity.

As a whole, the sample means suggested the participants identified more with the statements regarding violence, winning (i.e., the urge to win), risk-taking (i.e., predisposition for high-risk behaviors), and social identity (i.e., the degree to which one associates themselves with the roles of an athlete), while they felt less related to the statements making up the power over women (i.e., perceived control over women in personal and social constructs), playboy (i.e., yearning for many sexual relationships and emotional separation from sex partners), and exclusivity (i.e., the amount one's self-worth is established through playing sports) subscales.

As the length of involvement in contact sports increases, the public seems to exhibit an increased level of tolerance for aggressive behavior as part of the game or just "boys being boys" (Fields et al, 2007). The culture of contact and collision sports, especially when masculinity norms are promoted, is one in which violence in athletics is more than tolerated; it is encouraged (Pappas et al, 2004). Pairing such practices with the knowledge that the longer athletes are involved in sports, the stronger the athletes' 
adherence to that sport's cultural norms, is troubling if those norms spill over into their non-sporting lives. The current study's findings regarding the violence subscale provide another reason for adjusting the way aggression is portrayed in collision sports. Kreager (2007) also found that collision sport athletes, such as football and wrestling, were more likely to be involved in a serious fight as compared to baseball players, basketball players, tennis players, and non-athletes. Future research should continue to focus on multiple sports to gain a greater understanding of the differences in behaviors and beliefs between the athletes in collision, contact, and non-contact sports.

Results of the MANOVA indicated that, regardless of the sport the athletes excelled best at, these athletes had similar levels of views on masculinity. In fact, violence was the only subscale that showed a significant difference between groups. The collision group showed a significantly higher proclivity for violence as compared to the contact group. This finding provides insight into the culture surrounding collision sports and its influence on the athletes participating. The violence subscale is defined as "proclivity for physical confrontations," and consists of statements such as, "sometimes violent action is necessary," (Parent \& Moradi, 2009, p. 2). The aggressive nature surrounding collision sports can impact how athletes view violent acts and may lead to the legitimization of athletes' own aggressive tendencies. Bredemeier, Shields, Weiss, \& Cooper (1987) found boys who justified aggressive sporting plays were significantly correlated to having an "interest in high-contact sports, but not other sports, [which] may indicate that the normative structure of sport plays a role in legitimating aggressive game tactics and/or encouraging the involvement of boys who believe athletic aggression is appropriate," (p. 58). Further, high-contact high school athletes were more aggressive 
after provocation than low-contact high school athletes (Huang, et al., 1999). In the Huang study, participants were told to press a button for earning points, taking away points from someone else ("the aggressive response"), or the "escape response" button. Those who played high contact sports pressed the aggressive response button more often after perceiving that another participant took points from them. Although Huang and colleagues' (1999) study examined reactive aggressiveness, while the current study asked participants to identify how much they agree with specific statements, the results of each study coincide showing high contact sport athletes were more likely to be more aggressive compared to low contact sport athletes. Without a proper model of fair play, adolescents who play aggressive sports tend to continue this pattern of violence within sports (Bandura, 1973; Lemieux et al., 2002) that could lead to violence outside of sports (Pappas et al, 2004).

It is important to note that, although this study provided support for the previous literature mentioned above, the differences between the collision group and the contact and non-contact groups for the violence subscale was not very large. In fact, although the results may be statistically significant, the practical significance of these differences may be low. The fact that the non-contact group mean was higher than the contact group is interesting and adds to the need to reexamine these groups in future studies. Additionally, for all other CMNI subscales, there were not significant differences between the three groups. Overall, the collision, contact, and non-contact groups did not differ in regards to their views on hegemonic masculinity. This could be due to less accurate memories of how they felt when they were playing sports in high school because of the lapse in time between their participation in sports and their participation in the current study. 
Violence was positively correlated to the highest number of other subscales. This finding indicates that if a college-aged male displayed violent behavior, he would be more likely to conform to the related subscales as well (i.e., winning, risk-taking, playboy, heterosexual self-presentation, social identity, and negative affectivity). However, primacy of work (i.e., viewing work as a priority focus in life) was negatively correlated to heterosexual self-presentation (i.e., desire to be viewed as heterosexual), as well as to violence. This suggests that if one is more focused on their work, they would be less likely to conform to the hegemonic masculine norms of presenting oneself as macho or acting tough and vice versa. It is important to note the current study surveyed college students, who may or may not be working, therefore the responses to questions regarding work may reflect more or less interest in and amount of work depending on their schedules. As seen in Table 4.4 the correlations in this study were relatively low. This result could be due to the fact the participants were answering the survey retrospectively. For example, they may remember their experiences regarding certain subscales more accurately than others and/or life experiences since high school may impact their recollections. While the mean age of the participants was 22 years old, which may not seem far removed from their high school sporting days, college is a time when students are immersed in new experiences, often with new people and even new cultures. This flood of experience affects athletic identity and views of masculinity. The relatively low correlations in this study differs from Mahalik and colleagues. (2003), who developed the CMNI, because they found all of the CMNI subscales were positively correlated to each other. Albeit, their correlations were fairly low even though they were significant. 
Steinfeldt \& Steinfeldt (2012) found that athletic identity was correlated to all but emotional control and playboy. They concluded that higher athletic identity was positively correlated to traditional masculine norms. However, the results of the current study did not support this finding. Instead, social identity and negative affectivity only correlated to three of the CMNI subscales (winning, violence, and heterosexual selfpresentation), while exclusivity only correlated to two CMNI subscales (emotional control and self-reliance). The positive correlations of social identity (amount an athlete views him/herself as an athlete) and negative affectivity (extent an individual experiences negative affect when undesired outcomes occur in sport) (Brewer \& Cornelius, 2001) to winning, violence, and heterosexual self-presentation could indicate that the participants in this group viewed their athletic experiences as presenting themselves as tough and macho. Exclusivity (the amount one's self-worth is established through partaking in athletics) of the current study's participants related more to being in control and independent. The small number of significant correlations could, again, be due to the fact that the participants answered the survey retrospectively. Further, not all of the participants were currently athletes, and some did not play sports at all. This may have had an effect on the athletic identity part of the survey.

Sport participation can be associated with both benefits and costs to individuals and society, in general. For example, playing sports increases one's physical activity, which is generally seen as a positive and healthy outcome, but participation could also lead to injury (Merkel, 2013). This study adds another aspect of sport participation that can be examined in a negative light as well as a positive one. Of the three athletic identity subscales, only exclusivity was positively correlated to a CMNI-46 subscale: self- 
reliance. Self-reliance is defined as "aversion to asking for assistance," (Parent \& Moradi, 2009, p. 176). Therefore, according to the results of the current study, the more participants felt their self-worth was dependent on their athletic participation in high school, the less they asked for assistance when they need help mentally, physically, and/or emotionally. Although this is not a distinction between which type of sport they played in high school and the effects were small, these results illustrate ways that conformity to masculine norms can lead to adaptive behavior (e.g., learning to be selfsufficient through sport) or maladaptive behavior (e.g., a reluctance to ask for assistance in group situations) (Wong, Ho, Wang, \& Miller, 2016).

\section{Limitations}

The lack of significant results could relate to social desirability and potentially sensitive topics in the survey, considering other factors (e.g., sexual orientation), sample size, the fact that participants were answering retrospectively, and having more than half of the participants playing multiple sports in high school. Social desirability is the inclination of participants to provide answers that are more socially acceptable and bring about a more positive image than their true answer. Mahalik et al. (2003) found that masculine norms were related to social desirability and explained that while feminine norms (e.g., being nurturing) are normally pro-social, traditional masculine norms can be seen as politically incorrect (e.g., playboy) and illegal (e.g., violence). Therefore, the negative connotations that come along with certain aspects of masculine norms affect the self-report method of investigating these topics (Mahalik, et al., 2003) and, thus, coming up with innovative ways to reduce or eliminate social desirability is extremely important. 
In order to address this limitation, the researchers asked the professor to step out of the classroom and passed a survey to every student in the class (male or female), while asking only those who identify as male to participate. The participants were also told that the survey was completely anonymous, as their names were not collected. However, there is still a chance of social desirability due to the sensitive topic that is being investigated in the present study. For example, it will never be known if the participants want to be known as a playboy or if they want to be seen as non-violent. As suggested in Wong, Ho, Wang, and Miller (2016), another way to address social desirability is to find or create a measure or tool that can examine these questions less explicitly. Given the difficulty of that approach, another way to minimize the effect of social desirability could be to focus on constructs of masculinity that are less sensitive (Wong, Burkley, Bell, Wang, \& Klann, 2017).

Additional limitations may have impacted the results. Other aspects of social identity, such as sexual orientation, social class, race/ethnicity, and religion could also interact with conformity to masculine norms and athletic identities. While some of these factors were asked in the demographic questions, they were not factored into the analyses. Another limitation is the current study consisted of less than on hundred participants. Having a small sample size decreases the statistical power of a study. Similar studies, like Steinfeldt \& Steinfeldt (2012), had sample sizes in the hundreds. Finally, we relied on participants answering the survey questions accurately; however, the retrospective nature of the survey could be a limitation because participants might not remember their experiences accurately. 
One further limitation regards the fact that many of the participants played multiple different sports in high school, with more than half playing three or more sports. Therefore, it is difficult to determine if their sporting ideals and behaviors stem from just the sport they excelled at or if it is a collaboration of multiple sporting cultures. It would be pertinent for researchers to come up with a methodology that could examine how one specific sporting culture affects the athletes' beliefs.

\section{Delimitations}

The examination of conformity to masculine norms and athletic identity in this study was limited to an exploration of young male adults attending college who were presumed to have had sport experience in their past, based on their current interest in the study of kinesiology. The authors were interested in examining the impact of sport type (e.g., collision, contact, non-contact) and to consider the role of sport type-culture based on sustained involvement in that culture. To that end, it was originally decided to survey current college athletes based on their presumed longevity in and commitment to their sport. Efforts to distribute an online survey to active student-athletes in Division I, II, and III universities in the Pacific Northwest via athletic directors were for naught. Most athletic directors did not respond to recruitment email with less than ten responding that they would not be passing along the survey. At least one athletic director did provide the survey link to athletes (14 student-athletes took the online survey). Gaining access to student-athletes as research participants was difficult - a finding reinforced by other sport studies scholars in academic listservs who shared similar stories of blocked access.

Due to these recruitment difficulties, the population focus shifted to college students who presumably also had sport experience. Kinesiology courses were chosen 
because it was thought that Kinesiology students would be more likely to have past athletic experience given their current interest in studying physical activity. Additionally, Kinesiology majors were presumably more likely to remain physically active, providing for a continued athletic identity regardless of participating in an organized sport. Despite the shift in populations away from elite-level athletes, the exploration of questions about sport type, conformity to masculine norms and athletic identity will provide a useful expansion of knowledge about the role of sport in young adult males' reported attitudes and behaviors.

\section{Suggestions for Future Research}

Athletes' behaviors have become much more visible in light of technological advances and social media, and studies regarding their behavior and inclinations have become much more prevalent. Adherence to masculine norms and athletic identity amongst athletes are important topics for researchers to continue to examine. For example, scholars could build off of this study by surveying current athletes and adding other measures, such as video examples of aggressive behaviors, in order to gain further data from a single sample set due to the difficulty of gaining access to current athletes. This would help determine if certain measures affect the results or if the sample beliefs on aggression follow a similar trend throughout differing measures. Another way to avoid the accessibility issues of collegiate athletes would be to survey current high school students. It would be interesting if researchers could survey student athletes while they were in high school and then survey them again when they are in college. Even if not all of the high school athletes played college sports, it would provide results indicating how athletic identity and masculine norms evolve through time, determine if athletic identity 
increases at high levels of competition, and explore whether or not the flood of experiences that occur in college affect athletic identity and adherence to masculine norms.

To confront the limitation of sample size, researchers should survey more athletes and increase the statistical power. A suggestion for obtaining a larger sample size and a more generalizable result is to study and compare the results of athletes from many different age groups (children, teenagers, college athletes, and professional athletes) as well as from different regions, even nationally and internationally. Casting a broader net would provide further results regarding athletic identity and how it may or may not evolve the longer one plays sports and could also be used to explore how one's culture plays into athletic identity. Researchers should also consider observing the sexual orientation of the athletes and the ideologies surrounding the culture of certain sports, due to the fact that many sports, such as football and hockey, have more homophobic atmospheres (Adams, Anderson, \& McCormack, 2010; Steinfeldt \& Steinfeldt, 2012).

In regard to hegemonic masculine norms, researchers should focus studies on how coaches interact with players in game-time situations, as well as during practices. Studying how the coach expect and respond to on-field violence and aggression will help researchers understand how the culture of sporting violence is perpetuated within certain sports. Another avenue to examine hegemonic masculinity within the sporting culture is to study how the media portrays violent tackles or plays. Tracking the trends on if these situations are characterized as desirable or negative will give researchers a better idea of the larger sporting culture at hand. Either way, understanding where the desire to be more violent in sports comes from (i.e., coaches, the media, etc.) will give researchers and 
administrators a better idea of how to recreate the culture to be less reliant on hegemonic masculine norms.

It is important for coaches, parents, schools, and scholars to understand how the culture surrounding collision sports can affect what male athletes believe and how they behave. More studies need to be conducted regarding how hegemonic masculine norms and athletic identity could affect adolescents physically, socially, and psychologically. Sports psychologists should examine how the coaches and players interact in high contact sports in order to better understand the culture of aggression and the socialization process of hegemonic masculine norms (Fields et al, 2007; Messner, 2015; Murnen \& Kohlman, 2007; Young, 1993). Continuing to research these topics should provide additional insights into athletes' behaviors and proclivities. Educators, athletic directors, scholars and advocates can use this information to assist those individuals working with athletes to promote health and well-being in the athlete population and for those in their communities. 


\section{REFERENCES}

Adams, A., Anderson, E., \& McCormack, M. (2010). Establishing and challenging masculinity: The influence of gendered discourses in organized sport. Journal of Language \& Social Psychology, 29, 278-300.

Bandura, A. (1973). Aggression: A social learning analysis. Englewood Cliffs, NJ: Prentice-Hall.

Bredemeier, B. J., Shields, D. L., Weiss, M. R., \& Cooper, B. A. B. (1987). The relationship between children's legitimacy judgments and their moral reasoning, aggression tendencies, and sport involvement. Sociology of Sport Journal, 4, 4860.

Brewer, B. W., Van Raalte, J. L., \& Linder, D. E. (1993). Athletic identity: Hercules' muscles or Achilles heel? International Journal of Sport Psychology, 24(2) 237254.

Brewer, B. W., \& Cornelius, A. E. (2001). Norms and factorial invariance of the athletic identity measurement scale. Academic Athletic Journal, 15, 103-113.

Clay, R. A. (2012). Redefining masculinity: Three psychologists strive to build a 'better' man. American Psychological Association, 43(6), 52. Retrieved from http://www.apa.org/monitor/2012/06/masculinity.aspx.

Cortina, J. M. (1993). What is the coefficient alpha? An examination of theory and applications. Journal of Applied Psychology, 78(1), 98-104. http://dx.doi.org/10.1037/0021-9010.78.1.98.

Fields, S. K., Collins, C. L., \& Comstock, R. D. (2007). Conflict on the courts: A review of sports-related violence literature. Trauma, Violence, and Abuse, 8(4), 359-369. 
Gee, C. J. \& Leith, L. M. (2007). Aggressive behavior in professional ice hockey: A cross-cultural comparison of North American and European born NHL player. Psychology of Sport and Exercise, 8, 567-583.

Grange, P. \& Kerr, J. H. (2011). Do elite athletes renowned for their aggressive play transfer aggression to nonsport settings? A qualitative exploratory study. Journal of Aggression, Maltreatment, and Trauma, 20(4), 359-375.

Guivernau, M. \& Duda, J. L. (2002). Moral atmosphere and athletic aggressive tendencies in young soccer players. Journal of Moral Education, 31(1) 67-85.

Hogg, M. A. \& Reid, S. A. (2006). Social identity, self-categorization, and the communication of group norms. Communication Theory Journal, 16, 7-30. doi:10.1111/j.1468-2885.2006.00003.x.

Huang, D. B., Cherek, D. R., \& Lane, S. D. (1999). Laboratory measurement of aggression in high school age athletes: Provocation in a nonsporting context. Psychological Reports, 85, 1251-1262.

Identity. (n.d.) In Your Dictionary online. Retrieved from http://www.yourdictionary.com/identity.

Keeler, L. A. (2007) Differences in sport aggression, life aggression, and life assertion among adult male and female collision, contact, and non-contact sport athletes. Journal of Sport Behavior, 30(1), 57-76.

Kreager, D. A. (2007). Unnecessary roughness? School sports, peer networks, and male adolescent violence. American Sociological Review, 72, 705-724.

Lemieux, P., McKelvie, S. J., \& Stout, D. (2002). Self-reported hostile aggression in contact athletes, no contact athletes, and non-athletes. The Online Journal of Sport Psychology, 4(3), 42-56.

Mahalik, J. R. Locke, B. D., Ludlow, L. H., Diemer, M. A. Scott, R. P. J, Gottfried, M., \& Freitas, G. (2003). Development of the Conformity to Masculine Norms Inventory. Psychology of Men \& Masculinity, 4(1), 3-25. 
Marasescu, M. R. (2014). Aggressive behavior of elite athletes. Contemporary Readings in Law and Social Justice, 6(1), 98-103.

McCray, K. L. (2015). Intercollegiate athletes and sexual violence: A review of literature and recommendations for future study. Trauma, Violence, \& Abuse, 16(4), 438443.

McDonald, M. G. (1999). Unnecessary roughness: Gender and racial politics in domestic violence media events. Sociology of Sport Journal, 16, 111-133.

Merkel, D. L. (2013). Youth sport: Positive and negative impact on young athletes. Journal of Sports Medicine, 4, 151-160.

Messner, M. A. (2015). Male athletes, injuries, and violence. In D. Karen \& R. E. Washington (Eds.), Sociological perspectives on sport: The games outside the games (pp. 446-455). London \& New York: Routledge.

Moesch, K., Birrer, D., \& Seiler, R. (2010). Differences between violent and non-violent adolescents in terms of sport background and sport-related psychological variables. European Journal of Sport Science, 10(5), 319-328.

Murnen, S. K. \& Kohlman, M. H. (2007). Athletic participation, fraternity membership, and sexual aggression among college men: A meta-analytic review. Sex Roles, 57, 145-157.

National Collegiate Athletic Association (2014). 2014-2015 sports medicine handbook. Indianapolis, IN: National Collegiate Athletic Association.

Nunnally, J. C. \& Bernstein, I. R. (1994). Psychometric theory. McGraw-Hill, New York, NY.

Pappas, N. T., McKenry, P. C., \& Catlett, B. S., (2004). Athlete aggression on the rink and off the ice: Athlete violence and aggression in hockey and interpersonal relationships. Men and Masculinities, 6(3), 291-312.

Parent, M. C. \& Moradi, B. (2009). Conformity factor analysis of the conformity to masculine norms inventory and development of the conformity to masculine norms inventory-46. Psychology of Men \& Masculinity, 10(3), 175-189. 
Schmitt, N. (1996). Uses and abuses of coefficient alpha. American Psychological Association, Inc., 8(4), 350-353.

Skinner, B. F. (1957). Verbal behavior. Englewood Cliffs, NJ: Prentice-Hall.

Steinfeldt, M. \& Steinfeldt, J. A. (2012). Athletic identity and conformity to masculine norms among college football athletes. Journal of Applies Sport Psychology, 24, 115-128.

Thyer, B. A. \& Myers, L. L. (1998). Social learning theory. Journal of Human Behavior in the Social Environment, 1(1), 33-53.

Visek, A. J., Watson, J. C., Hurst, J. R., Maxwell, J. P. \& Harris, B. S. (2010). Athletic identity and aggressiveness: A cross-cultural analysis of the athletic identity maintenance model. International Journal of Sport \& Exercise Psychology, 8, 99116.

Walton, T. (2001). The Sprewell/ Carlesimo episode: Unacceptable violence or unacceptable victim? Sociology of Sport Journal, 18, 345-357.

Wong, Y. T., Burkley, M., Bell, A. C., Wang, S.-Y., \& Klann, E. M. (2017). Manly to the core: Measuring men's implicit masculine self-concept via the semantic misattribution procedure. Personality and Individual Differences, 104, 320-325. http://dx.doi.org/10.1016/j.paid.2016.08.026.

Wong, Y.J., Ho, M.H.R., Wang, S.Y., \& Miller, I.S.K. (2016) Meta-analyses of the relationship between conformity to masculine norms and mental health-related outcomes. Journal of Counseling Psychology, 64 (1). 89-93.

Young, K. (1993). Violence, risk, and liability in male sports culture. Sociology of Sport Journal, 10, 373-396. 
APPENDIX A 


\section{Demographic Questions}

1. How old are you?

2. What year in school are you?

$$
1^{\text {st }} \text { Year } 2^{\text {nd }} \text { Year } 3^{\text {rd }} \text { Year } 4^{\text {th }} \text { Year } 5^{\text {th }} \text { Year } 6^{\text {th }} \text { Year }
$$

3. What is your race/ethnicity (Select all that apply)

American Indian Asian Black/African American Hispanic American or Latino/a

Native Hawaiian or Pacific Islander White/European American

Prefer not to respond Write in:

4. What is your father/male guardian's highest level of education? (Choose highest)

High School Some College Bachelor's Degree Master's Degree

J.D., Ph.D., or M.D. I don't know

5. What is your mother/female guardian's highest level of education? (Choose highest)

High School Some College Bachelor's Degree Master's Degree

J.D., Ph.D., or M.D. I don't know

6. Sport Experience: List in the chart below the sports you played in high school, if any.

\begin{tabular}{|c|c|c|}
\hline SPORT & $\begin{array}{l}\text { GRADES PLAYED ON HIGH } \\
\text { SCHOOL TEAM }\end{array}$ & $\begin{array}{l}\text { GRADES PLAY ON NON-HIGH } \\
\text { SCHOOL TEAM WHILE IN HIGH } \\
\text { SCHOOL }\end{array}$ \\
\hline Example: Soccer & $J V-9^{\text {th }}$, Varsity- $10^{\text {th }}, 11^{\text {th }}, 12^{\text {th }}$ & Club- $-9^{\text {th }}-12^{\text {th }}$ \\
\hline & & \\
\hline & & \\
\hline & & \\
\hline & & \\
\hline & & \\
\hline & & \\
\hline & & \\
\hline & & \\
\hline
\end{tabular}


7. Which sport did you excel most at?

8. How many years did you played the sport you excelled most at?

9. Which position within the sport you excelled most at did you play?

10. Do you currently play a varsity college sport? If so, which sport? 
APPENDIX B 


\section{Conformity to Masculine Norms 46 and Athletic Identity}

Thinking about your own actions, feelings, and beliefs, please indicate how much you personally agree or disagree with each statement by circling "0" for Strongly Disagree, "1" for Disagree, "2" for Agree, or "3" for Strongly Agree. There are no right or wrong responses to the statements. You should give the responses that most accurately describe your personal actions, feelings, and beliefs. It is best if you respond with your first impression when answering.

\begin{tabular}{|c|c|c|c|c|}
\hline & $\begin{array}{r}\text { Str } \\
\text { Disagree }\end{array}$ & & & $\begin{array}{r}\text { Strongly } \\
\text { Agree }\end{array}$ \\
\hline In general, I will do anything to win. & 0 & 1 & 2 & 3 \\
\hline If I could, I would frequently change sexual partners. & 0 & 1 & 2 & 3 \\
\hline I hate asking for help. & 0 & 1 & 2 & 3 \\
\hline I believe that violence is never justified. & 0 & 1 & 2 & 3 \\
\hline Being thought of as gay is not a bad thing. & 0 & 1 & 2 & 3 \\
\hline In general, I do not like risky situations. & 0 & 1 & 2 & 3 \\
\hline Winning is not my first priority. & 0 & 1 & 2 & 3 \\
\hline I enjoy taking risks. & 0 & 1 & 2 & 3 \\
\hline I am disgusted by violence. & 0 & 1 & 2 & 3 \\
\hline
\end{tabular}




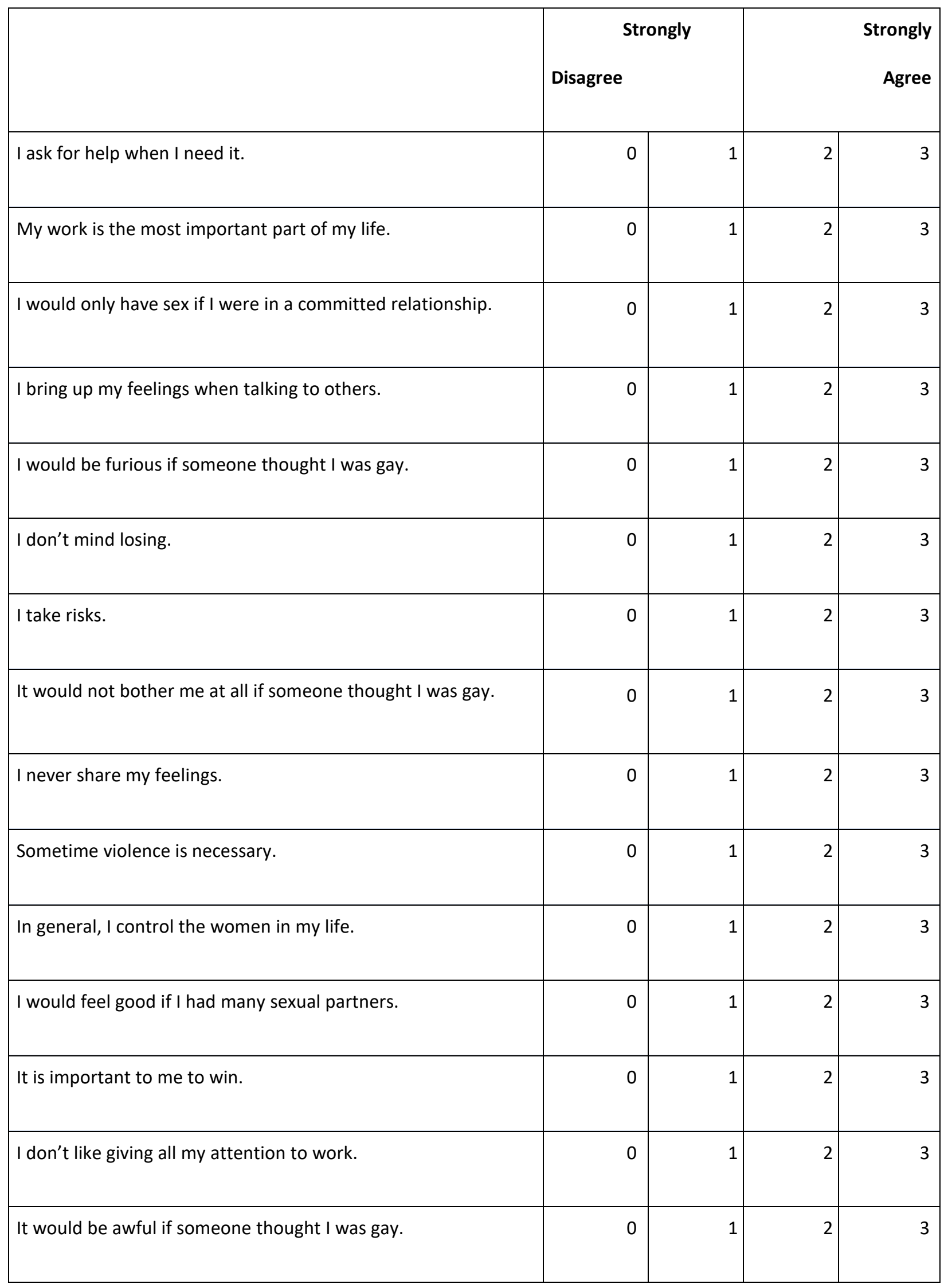




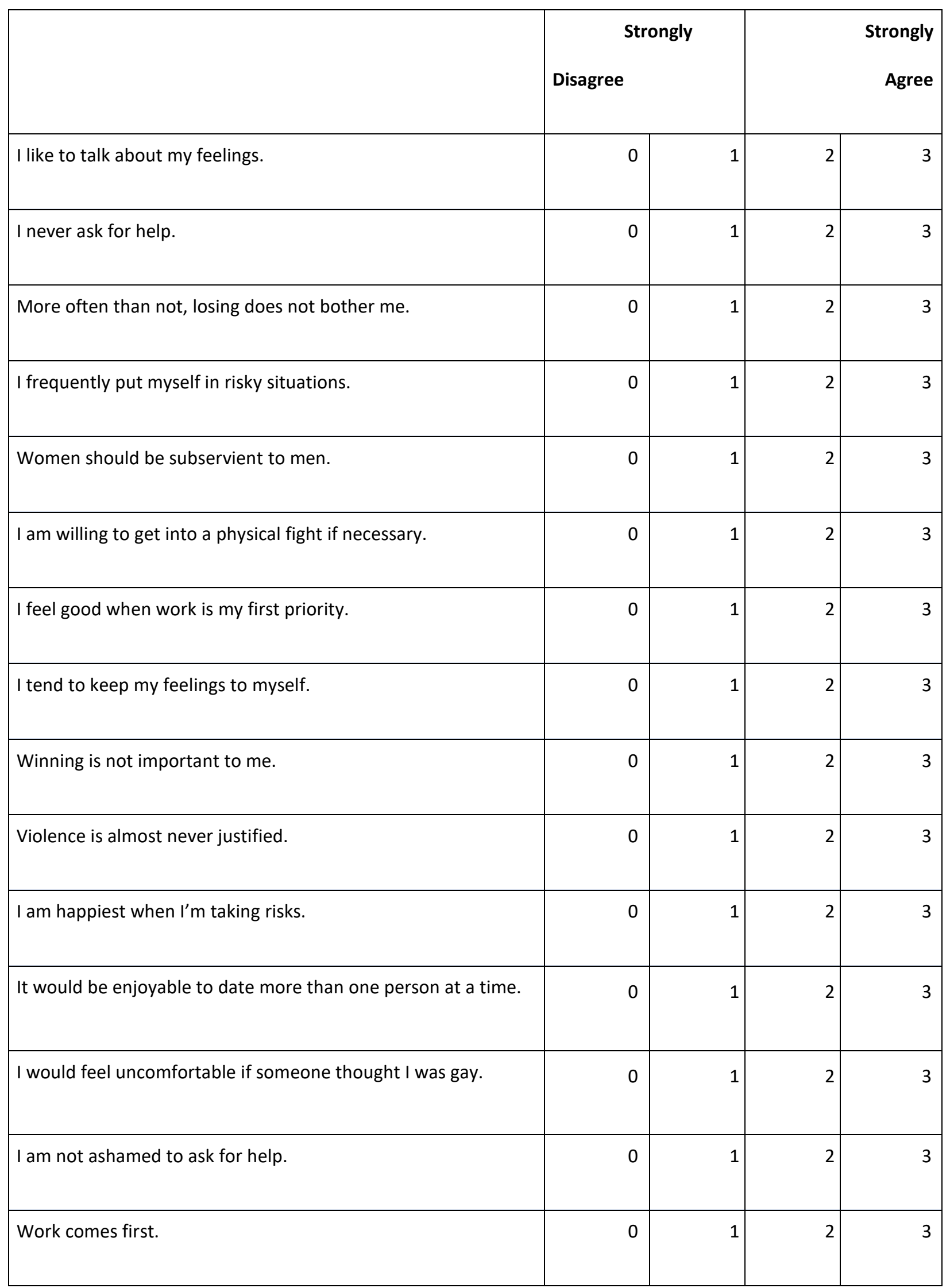




\begin{tabular}{|l|r|r|r|}
\hline & \multicolumn{2}{|c|}{ Strongly } & \multicolumn{2}{|c|}{ Strongly } \\
\hline I tend to share my feelings. & Disagree & 1 & 2 \\
\hline No matter what the situation, I would never act violently. & 0 & 1 & 2 \\
\hline Things tend to be better when men are in charge. & & & \\
\hline It bothers me when I have to ask for help. & 0 & 1 & 2 \\
\hline I love it when men are in charge of women. & 0 & 1 & 2 \\
\hline I hate it when people ask me to talk about my feelings. & 0 & 1 & 2 \\
\hline I try to avoid being perceived as gay. & 0 & 1 & 3 \\
\hline
\end{tabular}


APPENDIX C 


\section{7-Item Version of Athletic Identity Measurement Scale (AIMS)}

Please circle the number that best reflects the extent to which you agree or disagree with each statement regarding your sport participation.

1. I consider myself an athlete.

$\begin{array}{lllllllll}\begin{array}{l}\text { Strongly } \\ \text { Disagree }\end{array} & 1 & 2 & 3 & 4 & 5 & 6 & 7 & \begin{array}{l}\text { Strongly } \\ \text { Agree }\end{array}\end{array}$

2. I have many goals related to sport.

$\begin{array}{lllllllll}\begin{array}{l}\text { Strongly } \\ \text { Disagree }\end{array} & 1 & 2 & 3 & 4 & 5 & 6 & 7 & \begin{array}{l}\text { Strongly } \\ \text { Agree }\end{array}\end{array}$

3. Most of my friends are athletes.

$\begin{array}{lllllllll}\text { Strongly } & 1 & 2 & 3 & 4 & 5 & 6 & 7 & \text { Strongly }\end{array}$

Disagree Agree

4. Sport is the most important part of my life.

$\begin{array}{lllllllll}\text { Strongly } & 1 & 2 & 3 & 4 & 5 & 6 & 7 & \begin{array}{l}\text { Strongly } \\ \text { Agree }\end{array} \\ \text { Disagree } & & & & & & & & \text { Agre }\end{array}$

5. I spend more time thinking about sport than anything else.

$\begin{array}{lllllllll}\begin{array}{l}\text { Strongly } \\ \text { Disagree }\end{array} & 1 & 2 & 3 & 4 & 5 & 6 & 7 & \begin{array}{l}\text { Strongly } \\ \text { Agree }\end{array}\end{array}$

6. I feel bad about myself when I do poorly in sport.

$\begin{array}{lllllllll}\begin{array}{l}\text { Strongly } \\ \text { Disagree }\end{array} & 1 & 2 & 3 & 4 & 5 & 6 & 7 & \begin{array}{l}\text { Strongly } \\ \text { Agree }\end{array}\end{array}$

7. I would be very depressed if I were injured and could not compete in sport. $\begin{array}{lllllllll}\text { Strongly } & 1 & 2 & 3 & 4 & 5 & 6 & 7 & \text { Strongly }\end{array}$ Disagree Agree 


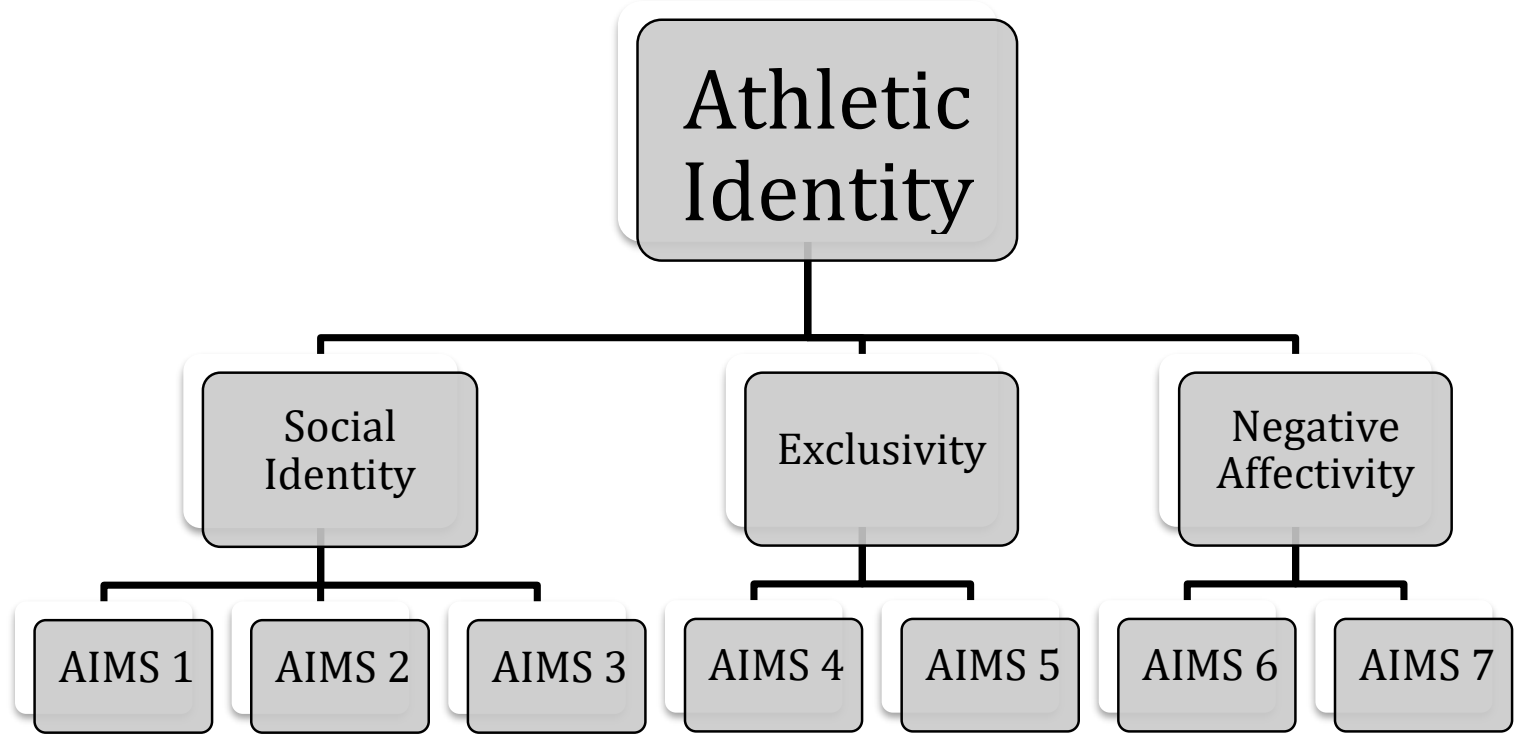


APPENDIX D 


\section{Consent Page for the Survey}

\section{Masculinity and Athletic Identity: A Retrospective Study}

Julie James, a graduate student at Boise State University, is conducting a

research study to evaluate masculinity and athletic identity in college students who identify as male. You are being asked to complete this survey because you are enrolled in a Kinesiology class this semester.

Participation is voluntary. The survey will take approximately 15 minutes to complete. You must be at least 18 years old to take this survey. This study involves no foreseeable serious risks. We ask that you try to answer all questions; however, if there are any items that make you uncomfortable or that you would prefer to skip, please leave the answer blank. For this research project, the researchers are requesting demographic information. The researchers will make every effort to protect your confidentiality. Your responses are anonymous and you will not be asked to provide your name.

If you have any questions or concerns, feel free to contact Julie or her faculty advisor:

Julie James, graduate student

Dr. Shelley

Lucas, Associate Professor

Department of Kinesiology

Department of

Kinesiology

(909) $560-9083$

(208) 426- 


\section{juliejames@u.boisestate.edu}

\section{smlucas@boisestate.edu}

If you have questions about your rights as a research participant, you may contact the Boise State University Institutional Review Board (IRB), which is concerned with the protection of volunteers in research projects. You may reach the board office between 8:00 AM and 5:00 PM, Monday through Friday, by calling (208) 426-5401 or by writing: Institutional Review Board, Office of Research Compliance, Boise State University, 1910 University Dr., Boise, ID 83725-1138.

If you would prefer not to participate, please do not fill out a survey. If you consent to participate, please complete the survey. 